Cómo citar este artículo: Bermúdez Quintana, E. M. (2015, enero-julio). Vivencias particulares de mujeres en procesos de movilidad humana. Rev. Cient. Gen. José María Córdova 13(15), 89-113

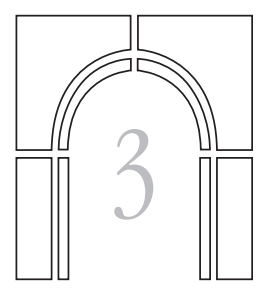

\title{
Vivencias particulares de mujeres en procesos de movilidad humana: dos miradas relativas a su bienestar*
}

Recibido: 15 de enero de 2014 - Aceptado: 2 de febrero de 2015

\author{
Particular Experiences of Women in Processes of Human Mobility: \\ some Views on Their Wellbeing
}

Expériences particulières des femmes dans des processus de mobilité humaine: regards sur leur bien-être

Experiências particulares das mulheres nos processos de mobilidade humana: um olhar sobre seu bem-estar

Elba Maria Bermúdez Quintana a

\footnotetext{
* Artículo investigación derivado de una adaptación y actualización de los resultados investigativos de la tesis doctoral de la autora, titulada: "La salud de las mujeres inmigrantes: una mirada desde la sociología", junto a las varias y propias reflexiones de la autora obtenidas desde un transcurrir de tiempo, en los temas de género, salud y migración.

a Universidad Politécnica de Valencia, Valencia, Espańa. Odontóloga del Colegio Odontológico Colombiano, Magíster en Administración de Salud de la Pontificia Universidad Javeriana de Bogotá y PhD en Economía y Gestión de la Salud de la Universidad Politécnica de Valencia. Actualmente es profesora de la Pontificia Universidad Javeriana de Bogotá-Facultad de Odontología y coordina el área de investigaciones de la Escuela Militar de Cadetes José María Córdova. Contacto: embq2012@gmail.com
} 
Resumen. El propósito de este artículo es analizar las emociones y experiencias que viven las mujeres migrantes colombianas en España, que se empeñan en llevar a cuestas grandes compromisos y responsabilidades para dar un futuro mejor, no solo a sus hijos e hijas, sino a su núcleo familiar, afectando su propio bienestar. Como parte del diseño metodológico se hicieron entrevistas semi-estructuradas tanto a mujeres como a profesionales de la salud y de servicios sanitarios, en la ciudad de Valencia, España. También se incluyen reflexiones de la propia autora, luego de haber regresado a su país de origen. Las mujeres migrantes son protagonistas de gran parte de la movilidad humana, como grandes remesadoras que envían a sus familias para brindarles un mejor sustento económico para que redunde en bienestar, muy a costa de su salud física, emocional, psicológica y económica. Sacrificio y la resiliencia se ven presentes en cada momento de su vida migrante.

Palabras clave: bienestar, feminización, género, migraciones, movilidad humana y salud.

Abstract. The purpose of this article is to analyze the emotions and experiences that live Colombian women migrants in Spain who are determined to fulfill great commitments and responsibilities to a better future for their own sons and daughters, as well as for their core family support, affecting their own wellbeing. As part of methodological design, semi-structured interviews were conducted with women and health professionals and healthcare workers, in the city of Valencia, Spain. Reflections of the author herself are also included, after returning to her country of origin. Women migrants are the protagonists of much of human mobility, as "remittance providers" in order for their families to ensure an economic wellbeing, even at the expense of their physical, emotional, psychological and economic wellbeing. Sacrifice and resilience are present in every moment of his migrant life.

Keywords: feminization, gender, migration, health, human mobility and welfare

Résumé. Le but de cet article est d'analyser les émotions et les expériences que vivent les femmes colombiennes migrantes en Espagne, qui sont déterminés à remplir de grands obligations et responsabilités pour assurer un meilleur avenir de leurs filles et de leurs fils, et aussi de leur noyau familial, affectant leur propre bien-être. Dans le cadre du design méthodologique, des entrevues semi-structurées ont été menées avec des femmes et des professionnels de la santé et des services sanitaires, dans la ville de Valence, en Espagne. Les réflexions de l'auteur elle-même sont également incluses après le retour dans son pays d'origine. Les femmes migrantes sont les protagonistes de la majeure partie de la mobilité humaine, comme des " fournisseuses d'envoi » afin de procurer une aide financière d'urgence à leurs familles, même au détriment de leur propre bien-être physique, émotionnel, psychologique et économique. Le sacrifice et la résilience sont présents à chaque instant de leur vie migrante.

Mots-clés : bien-être, féminisation, genre, migration, mobilité humaine et santé.

Resumo. O objetivo deste artigo é analisar as emoçôes e experiências que vivem as mulheres colombianas imigrantes em Espanha, que estão determinadas a cumprir grandes compromissos e responsabilidades para dar um futuro melhor aos seus filhos e filhas, e apoio à saúde da família, afetando o seu próprio bem-estar. Como parte do desenho metodológico, entrevistas semi-estruturadas foram realizadas com mulheres e profissionais de saúde e do serviço de saúde, na cidade de Valência, na Espanha. Reflexôes da própria autora também estão incluídas, após o retorno ao seu país de origem. As mulheres migrantes são protagonistas de grande parte da mobilidade humana, como as principais provedoras de suas famílias para brindar-lhes um melhor bem-estar economico, mesmo à custa da sua própia saúde emocional, física, psicológica e econômica. O sacrifício e a resiliência estão presentes em todos os momentos da sua vida migrante.

Palavras-chave: bem-estar, feminização, gênero, migração, mobilidade humana e saúde. 
Afirmar la propia identidad es, para todos y cada uno, legitimo. No debemos ruborizarnos si preferimos los nuestros a los desconocidos. Si vuestra madre o vuestro hijo fueron víctimas de la violencia, esos recuerdos os harán sufrir más que la muerte de gente desconocida, y procuraréis con más ahinco mantener viva su memoria.

Todorov, 2002, p. 2009.

\section{Introducción}

En el artículo se estudian las vivencias particulares de mujeres colombianas en procesos de movilidad humana, respecto a su bienestar, incluyéndome yo misma como sujeto de análisis, a propósito de las experiencias propias de la autora, durante sus años de residencia en Espańa. En este sentido, la investigación hace acopio en gran medida de métodos cualitativos, en la modalidad de investigación-acción participativa, integrando dos miradas de mi experiencia migratoria, una académica y otra laboral, matizada por enfoques psicológicos y sociológicos. Sin embargo, el empleo de métodos cuantitativos fue de gran utilidad en estudios poblacionales de mujeres migrantes. Así pues, la integración de métodos cualitativos y cuantitativos fue fundamental en el desarrollo de la investigación, hasta el punto que consideramos que el deslinde de estos dos métodos es casi imposible en este tipo de investigación social.

Pero la investigación también se beneficia del concepto de memoria como género literario, aplicable a la historia y a la ciencia, en el sentido que le dio al término el teórico del lenguaje Tzvetan Todorov — citado en el epígrafe- en su libro Memoria del mal, tentación del bien (Todorov 2009), y que para nuestro caso particular se traduce en una memoria - personal y académica - del proceso migratorio, que ha sido decantada varios años después, una vez de regreso y radicada en Colombia, e incluso enriquecida por nuevas reflexiones académicas sobre mi experiencia migratoria vivida in situ. Ello justifica el estilo en primera persona para estudiar el fenómeno de movilidad humana. Así las cosas, la objetividad académica y la subjetividad de vivencias personales confluyen aquí como objeto de investigación. Los relatos de mujeres como protagonistas de migración provienen de mi disertación doctoral defendida en la Universidad Politécnica de Valencia.

El trabajo consta de ocho partes. En "Descubrir el proceso migratorio" — que abre la discusión - se hace un análisis de la situación a propósito del "síndrome del inmigrante" y de la "discriminación laboral de las mujeres inmigrantes", esto es, desde un punto de vista psicológico y sociológico, pero también personal, desde la perspectiva de la investigación-acción participativa mencionada. La segunda parte, "La movilidad humana vista bajo una perspectiva del bienestar social" aborda diversos aspectos de la cuestión del bienestar social de la persona migrante: seguridad social, el caso de inmigrantes mujeres que se desempeñan en Espańa como trabajadoras domésticas o cuidadoras las personas de tercera y cuarta edad, en el contexto de lo que en Italia se denomina la "revolución oculta" (rivoluzione occulta), del proceso migratorio.

En "La feminización de las migraciones", la tercera parte del artículo, se evidencia el fenómeno de la feminización de las migraciones. La incorporación de la teoría de género en las 
movilidades humanas cobra fuerza con las primeras aproximaciones que hicieron expertos de la División de Poblaciones Unidas en 1998, con el fin de investigar sobre la dimensión social de este fenómeno durante el período comprendido entre 1965 y 1990. Los resultados de la investigación se apoyaron en los datos estadísticos obtenidos de los censos de población a partir del número de personas nacidas fuera del país, junto con información relativa al número de refugiados. Gracias a las estimaciones realizadas, hoy se sabe que hacia 1960 las mujeres representaban casi el 47\% de los migrantes. Desde entonces esa proporción ha ido en incremento, hasta llegar a un 48\% en 1990 y un 49\% en el año 2000 (Zlotnik, 2003, apud Tapia 2011, pp.115-147). Así mismo, los expertos también aducen que más del $13 \%$ de la población migrante del mundo es oriunda de Latinoamérica y el Caribe, es decir, unos 25 millones de personas, de las cuales un 50\% son mujeres (Rico, 2006). Esto nos permite corroborar que una muestra representativa de las emigraciones latinoamericanas se caracteriza por un incuestionable fenómeno de feminización de la movilidad humana internacional (Martínez, 2003). El motivo principal por el cual las mujeres latinoamericanas deciden emprender un proceso inmigratorio, es sin lugar a dudas, para dar bienestar a sus hijos, hijas y familias, gracias a las remesas obtenidas por el trabajo que obtengan en los países de destino (ONU, 2006a).

En "Las condiciones de los procesos migratorios afectan más a las mujeres que a los varones", la cuarta parte del artículo, se estudian las condiciones de los procesos migratorios de aquellas mujeres que decidieron emprender un proceso migratorio. La quinta parte, "La mujer inmigrante colombiana es la responsable del bienestar de su núcleo familiar", describe el rol de la mujer migrante para lograr el bienestar de su familia, así sea desde la distancia; situación que trae consigo grandes tensiones en sus emociones y estados emocionales y psicológicos. La sexta parte, "El derecho a la salud es fundamental para el bienestar de la mujer migrante colombiana”, consta del derecho a la salud, por parte de las mujeres y las repercusiones que se pueden evidenciar al respeto. La séptima parte, "Las opiniones de los trabajadores sanitarios", contiene las reflexiones que se tienen de las mujeres migrantes, los trabajadores de la salud del sistema sanitario de la ciudad de Valencia-España, ciudad en dónde fueron realizadas estas entrevistas. Desde esta postura, se pueden leer los imaginarios que se tienen sobre la población migrante. Para finalizar, la octava y última parte, "Los relatos de las mujeres colombianas inmigrantes", ofrece los relatos de las mujeres colombianas inmigrantes, desde un reconocimiento de su corporalidad y de su ser social; las condiciones de su propio cuidado y la relación del trabajo con respecto a la salud de ellas mismas.

El problema de investigación se centra en describir y evidenciar las emociones y experiencias que viven las mujeres migrantes colombianas en Espańa, como seres que se empeñan en llevar tras sus espaldas grandes compromisos para dar un futuro mejor, no solo a sus hijos e hijas, sino a su núcleo familiar. Estas cargas emotivas, afectan sin lugar a dudas su propio bienestar y su condición psicológica, mermando su resistencia y su integralidad. Con casi todo en contra, se encuentran verdaderos ejemplos de tenacidad y resiliencia.

Este documento es un aporte de elementos, evidencias y visibilización de aquellas mujeres que desde la "otra orilla", contribuyen al bienestar de sus familias, pero que desafortunadamente no son retribuidas ni reconocidas de manera suficiente en los principios de estados de bienestar, protección social, derecho a la salud y reconocimiento social, no solo en los países de origen, sino en los de destino. 


\section{Descubrir el proceso migratorio}

Cuando tomé la decisión de ir a realizar mi Doctorado en Economía y Salud en la Universidad Politécnica de Valencia en España, uno de los grandes temores que me asaltaban era abandonar una estabilidad emocional y laboral para someterme a un desarraigo familiar, económico, social y afectivo. A pesar de mis miedos, la emoción de experimentar y adentrarme en esa "otra orilla" —allende el Atlántico desde Colombia, y más acá de las Columnas de Hércules ${ }^{1}$ desde Europa-, perteneciente a una España pletórica de historias fascinantes, con espacios encantadores, mezclados por culturas moriscas e hispánicas, vividas en el regio palacio de La Alhambra (Fernández, $1941)^{2}$. Todo esto fue algo subyugador y se constituyó en un aliciente para asumir con entereza un proceso migratorio, personal y académico.

Pero mis temores no solo se hicieron realidad, sino que se convirtieron en sentimientos y realidades más intensas y profundas que mis propias sospechas. Migrar, en efecto, arrastra consigo un desarraigo físico, emocional y psicológico. Este conjunto de síntomas fue caracterizado por el psiquiatra catalán Joseba Atxotegui como sindrome de Ulises, o síndrome del inmigrante (cf. Atxotegui, 2000, pp. 88-100), y se identifica por siete duelos: 1) duelo por la familia y los amigos; 2) duelo por la pérdida del grupo étnico; 3) duelo por la pérdida de la lengua; 4) duelo por la separación de la cultura; 5) la pérdida del paisaje; 6) duelo por la pérdida del estatus social, y 7) duelo por los riesgos físicos. Este fenómeno psicológico y emocional ocurre, sobre todo, cuando se inmigra a una sociedad de mayor desarrollo económico. Llegar a un país más avanzado para establecerse en él implica en ciertos aspectos ser un extrańo en una sociedad dominante. En su desasosiego el inmigrante se siente, en ciertos espacios, deprimido y sin control de su propia vida.

\section{Dos miradas del proceso migratorio}

El estudio del proceso migratorio se está convirtiendo hoy en día en uno de los temas prioritarios de investigaciones sobre movilidades humanas que abordan problemáticas particulares del fenómeno inmigratorio, y que desafortunadamente, para la mayoría de las personas que padecen el síndrome de Ulises, viven situaciones agobiantes provocadas por niveles de estrés tan intensos que originan trastornos psicológicos a veces graves. El conjunto de síntomas que conforman este síndrome constituye hoy en día un problema emergente de salud pública en los países de acogida de las personas migrantes.

Una vez radicada en Espańa, viví durante once ańos todas las bondades y oportunidades que ofrece un país a un inmigrante, junto con momentos dolorosos. Dentro de ese contexto, dos hitos marcaron sendas miradas de mi experiencia migratoria, una académica y otra laboral.

\footnotetext{
${ }^{1}$ Hoy Estrecho de Gibraltar. (N. del E.)

2 La autora se refiere al castillo de La Alhambra, símbolo de la Espańa musulmana, arruinado después de la conquista de Granada, reconstruido por Carlos V, que encargó de su reconstrucción al célebre arquitecto Pedro de Machuca. (N. del E.)
} 


\section{La mirada académica del proceso migratorio de mujeres}

El primer hito, una mirada académica del proceso migratorio, fue la universidad donde hacía mis estudios de doctorado. El ambiente académico le dio sentido y valor a la construcción del marco teórico relativo al bienestar del inmigrante, para comprender el dolor emocional de verme ausente de la familia y amigos, de sentirme extranjera, a pesar de estar rodeada por gente que me arropaba ${ }^{3}$ de mis nostalgias. Cuando inicié el trabajo de campo, me acerqué a cada una de las mujeres que entrevisté, empecé a sentirme identificada con lo que se siente estar lejos del país y de los suyos, de la tierra, del entorno y de toda la red social que lo sustenta. Sin embargo, yo estaba en cierta forma protegida, por encontrarme inmersa en el ámbito académico, rodeada de un grupo profesoral y de compañeros y compañeras que vivían una atmósfera similar, como estudiantes de tercer ciclo. Todo ello me daba cierta seguridad y confianza, ya que me acomodaba a las circunstancias como si estuviese en Colombia, antes de inmigrar. En ese contexto, todo era cuestión de reconocer en aquellas personas los mismos códigos de convivencia y de gustos para que empezáramos a tejer acercamientos de amistad.

Con todo, muchas de estas mujeres no tuvieron la misma fortuna; se dedicaban a trabajos que no tenían nada que ver con su formación y experiencia laboral. Esta es la llamada "discriminación laboral de las mujeres inmigrantes", concepto que ha sido acuñado por Sonia Parella Rubio (2003), para referirse a la condición de mujeres inmigrantes que son "reclutadas en aquellos puestos de trabajo que no interesan a las mujeres autóctonas".

En la universidad, como estudiante, empecé a construir sentimientos de adaptación y de resignación, por el hecho de haber dejado a mi hijo al cuidado de mis padres, con diligente esmero por parte de mi madre y la satisfacción de mi padre de acogerlo en su hogar. En el día a día, mi hijo estuvo a cargo de mi madre, quien asumió con todo el amor y la rigurosidad, la crianza de su nieto, mientras yo me encontraba en el exterior, realizando estudios de doctorado. Esta situación confirmó, una vez más, que quienes asumen el rol de cuidadoras en Colombia son las mujeres. Por ello podemos hablar, en cierto sentido, de una feminización del cuidado (Vaquiro Rodríguez, Sandra, \& Stiepovich Bertoni, Jasna, 2010).

Salvo este gran dolor — que nunca me abandonó en mi condición de inmigrante- trabajar en la universidad como becaria y ocupar mi tempo en actividades de estudio y de investigación, más que apabullarme, me hacían crecer como profesional, además de sentirme identificada con el entorno universitario. Pero no solo estudié, sino que además viajé y conocí lugares emblemáticos y me perdí en pueblecitos de la España profunda, gracias al dinero que gané como becaria, persiguiendo costumbres, paisajes y buena cocina tradicional española. Puedo decir que conocí a fondo ese bello país, así que realicé sueńos que todo estudiante colombiano quiere cumplir cuando estudia fuera de su país: conocer otras culturas, adentrarse en la sociedad de acogida y aprovechar cada nuevo conocimiento.

3 Arropar es una expresión castiza de España que significa 'respaldar', 'proteger', 'acompañar'. La locución "estar arropado" vale por 'estar respaldado o acompañado'. (N. del E.) 


\section{La mirada laboral del proceso migratorio de mujeres}

Sin embargo, no todas mis experiencias fueron positivas. Fue entonces cuando experimenté el segundo hito que marcó mi experiencia migratoria; lo identifiqué cuando tuve que salir del mundo académico, al mundo laboral. Ese es un espacio en donde los migrantes luchábamos por un puesto de trabajo, demostrando más de lo que éramos, traduciendo modismos, callando asimetrías y discriminaciones, para que finalmente nos identificaran como "los de allă", "tan distintos y $\tan$ extraños" a "nosotros", los "de aquî".

El hecho de no saber manejar todos los códigos restringidos y elaborados de la comunicación (Bernstein, 1993, pp. 88-118), el acento tan particularmente marcado como lo es el español hablado en Espańa, los temores constantes de enfermar y el no poder trabajar para lo cual estaba formada y preparada, además de no estar arropada, en otras palabras, respaldada y acompañada, bajo la protección de esa red social — los amigos y la familia - que tanta influencia tiene en la configuración de nuestra personalidad $-\mathrm{y}$ en ese ser social muy particular que llevamos dentro-, no solo en los sencillos momentos de la vida cotidiana, sino en aquellos que son cruciales e impactantes, pero que muchas veces se traducen en procesos de vacio - entre la soledad y el coraje - de no podernos relacionar (Solé, 2004). Todo ello genera una constante sensación de nostalgia y, en más de una ocasión, no solo resta energía para el diario vivir, sino que se padece un gran cansancio energético y emotivo. Pareciera que nuestra mente hiciera un esfuerzo extra por sostenernos en entornos extraños. La falta de red social es quizás uno de los grandes duelos que se puede sentir cuando se extranjera. El vacío social, genera un gran vacío y por supuesto, un gran temor.

Aunque la inclusión del derecho a la emigración dentro del abanico de los derechos humanos es un hecho loable, lo cierto es que tal inclusión ha quedado vacía, ya que, casualmente, no se ha estipulado en la Declaración Universal de los Derechos del Hombre de 1948 la cara opuesta, esto es, la obligación de soportar la emigración o el deber correlativo de permitir la emigración. Es decir, se tiene el derecho reconocido universalmente de salir de un país, pero no se reconoce el derecho a llegar a ningún sitio (Soriano, 2001). Los países no desarrollan estrategias para construir sociedades de acogida y muy al contrario, pareciera que se desencadenaran una serie de acciones inhóspitas e incómodas, que afectan a unos y unas, más que a otros y a otras.

\section{La movilidad humana vista bajo una perspectiva del bienestar social}

Una vez que la persona migrante se ha incorporado al mercado de trabajo del país de acogida se plantea la cuestión de su protección por la seguridad social. A causa de la diferente concepción de los sistemas de seguridad social, de conformidad con las legislaciones de los diferentes países, los migrantes pueden ver que, si no se adoptan las disposiciones oportunas, por lo común pierden sus derechos de seguridad social, quedando el trabajador y su familia en situación de necesidad.

Una nueva especialidad laboral se está convirtiendo en el dominio privilegiado de las movilidades humanas. Las trabajadoras domésticas inmigrantes, tales como cuidadoras, damas de compañía o internas en los hogares de España y de Europa, proceden de países de Latinoamérica o del continente africano, donde las condiciones económicas y de seguridad las convierte en 
inmigrantes económicas. En este sentido, existe una complicidad indirecta y oculta entre los empleadores de servicio doméstico y la salud pública.

En el caso de España es mucho más barato permitir que las personas de tercera y cuarta edad y las familias, busquen mujeres migrantes que atiendan y cuiden a los mayores e incapacitados en sus domicilios, a través de mano de obra barata con necesidad de empleo proveniente de Latinoamérica o de Europa del Este, que promulgar leyes de protección social que den bienestar a estos colectivos con grandes necesidades y que son responsabilidad del Estado. Las administraciones responsables de la tercera y cuarta edad se ahorran la construcción y adecuación de Centros de Bienestar para Mayores, en donde no solo se les debe ayudar a solucionar los problemas de salud, sino que deben resolver sus problemas de afecto y de compañía. En Italia se le denomina a esta afluencia de ayuda doméstica como la "revolución oculta" (rivoluzione occulta). Se trata de "todo un cambio que tiene su origen en la apertura a escala internacional del mercado de trabajo asistencial. La demanda y la oferta asistencial han sabido ayudarse mutuamente, siguiendo vías desconocidas e imprevistas" (Meletti, 2004, p. 8).

Como ya se mencionó, son varias las situaciones en las que la trabajadora o el trabajador migrante puede quedar desprotegido, ya que son muchas las prestaciones que en los diferentes sistemas de protección se califican de "inexportables" desde el país de empleo, por ejemplo, la asistencia sanitaria, el seguro por desempleo y las asignaciones familiares; y por otro lado, la salida del país de origen puede suponer, muy seguramente, la pérdida de los derechos acumulados a una pensión en el mismo, teniendo que esperar en el país de destino el que se cumplan los requisitos para adquirirla. De todas estas diversas situaciones se puede derivar una denegación de justicia social y una discriminación injustificada entre nacionales y extranjeros (OIT, 1984).

El derecho a la salud adquirido por todo ser humano, a través del Derecho Coordinador de Seguridad Social, tiene como propósito orientar situaciones a quienes deciden salir de sus países de origen, en el sentido de que sean protegidos, al menos, del mismo modo que los nacionales; de tal suerte que el proyecto migratorio no les produzca una disminución o pérdida de sus derechos ya adquiridos o por aquellos que están por adquirir.

Varias de las investigaciones españolas que afrontan el tema sobre inmigración y salud, quedan en el plano de la mera descripción del fenómeno. Efectivamente, estos trabajos demuestran el hecho de saber quiénes son, cuántos son, dónde están, el tipo de servicios de salud que demandan, la descripción de los servicios demandados y los obstáculos encontrados durante la demanda y el acceso. Sin embargo, no van más allá de la aplicación de encuestas y queda vacía la problemática social (Asamblea Parlamentaria; Vásquez, 2002, pp. 505-508; López, 2002, pp. 492-497; Romani, 2002, pp. 498-504; PWC, 1999; Santamaría et al., 2002; Cots et al., 2002).

Cabe destacar el estudio realizado por Ramos et al. (2001), en donde a través de un estudio descriptivo y mediante la metodología cualitativa, analizan los problemas existentes en la atención sanitaria a los inmigrantes económicos, según la opinión de los profesionales socio-sanitarios, de la administración sanitaria y de los inmigrantes. Este es uno de los ejemplos en donde se avanza más allá, incluyendo a los actores sociales del problema.

Atxotegui también ha colaborado en investigaciones sobre duelo migratorio, desde la perspectiva psico-afectiva y sus consecuencias de ajuste y de acoplamiento social, cultural y moral, en la sociedad española (Tizón et al., 1986; Atxotegui, 2002). Desde el plano de la psiquiatría 
transcultural, se convierten en objeto de estudio las relaciones que se establecen entre los procesos migratorios, el estrés social y la salud mental.

Uno de los planteamientos más interesantes, de parte de Adriana María Gomes e Sousa, gran psicóloga feminista, refiere que el "Síndrome de Ulises" fue propuesto una vez revisadas y estudiadas las historias de vida de varones subsaharianos; por ello, ella propone el término de "Sindrome de Penélope" para asignarlo a mujeres que sufren signos y síntomas emocionales diferenciales, causados por sus procesos migratorios. Como bien dice la autora de esta propuesta

Las mujeres inmigrantes son las Penélopes del siglo XXI que empiezan a tejer su propio destino, son ellas mismas, en número cada vez más amplio, las que proponen y dirigen su vida, son ellas las que buscan el arco y se lanzan, se proyectan más allá de lo doméstico, al encuentro de un destino con mejores posibilidades. Aquí ellas son las protagonistas de su relato. El tapiz tejido por ellas crea redes que abren caminos para que otras mujeres, e inclusos varones, puedan beneficiarse de la migración, a pesar de los costes que ésta pueda conllevar en el decurso del proceso migratorio: el estrés y los malestares psicológicos. (Gomes, S.f.)

\section{La feminización de las migraciones}

Históricamente los movimientos migratorios han incluido a la mujer, pero ella ha sido subestimada como objeto de estudio, en aras de convertir en protagonista al varón. Michelle Perrot, autora del libro Mi historia de las mujeres, afirma que "Las mujeres han migrado en todas las épocas y por toda clase de motivos de manera más onerosa, menos aventurera que los hombres, porque necesitan justificación, contención, incluso apoyo" (S. p.).

Por su parte, la antropóloga Dolores Juliano plantea que

La idea de la inmigración femenina como dependiente de la masculina se apoya en un estereotipo muy consolidado, según el cual el hombre es más móvil geográficamente. La mujer se caracterizaría por permanecer, mientras que el hombre tendría unos itinerarios autónomos más amplios. Sin embargo, esto es falso en su conceptualización misma, dado que la inmensa mayoría de nuestras sociedades fueron patrilocales, lo que significa que el modelo tradicional de mujer es el de la mujer que abandona su hogar de origen para ir a vivir al lugar de su marido. Así podemos hablar de mujeres 'estructuralmente viajeras' en contraposición a la imagen estereotipada de mujeres 'accidentalmente viajeras'. Sin embargo, esta movilidad espacial resulta absolutamente invisible. (1994, pp. 23-32)

A pesar de haber sido invisiblizada de los procesos migratorios, la mujer ha cobrado un protagonismo reconocido, y en los últimos tiempos han ido adquiriendo mayor presencia en las investigaciones y estudios sobre migraciones. Uno de los trabajos pioneros ha sido el del profesor Mirjana Morokvásic. Allí, el autor introduce la perspectiva de género al considerar a las mujeres en los flujos migratorios, no solo como acompañantes sino también como autónomas.

La "feminización de las migraciones" ha dado lugar a una creciente producción académica, dando cuenta no solo de un gran aumento cuantitativo sino de los aspectos cualitativos. Tal es el caso de la transformación del modelo tradicional de mujer acompañante del varón, a un nuevo modelo que se evidencia notablemente en las migraciones de origen musulmán, al modelo de la 
migrante autónoma, como la situación de las migraciones realizadas por mujeres latinoamericanas. La inclusión de las mujeres y de la categoría género en los estudios sobre migraciones se vincula a la necesidad de explicar el aumento de la participación femenina en la migración internacional, además de analizar las particularidades de esta participación, el impacto en las áreas de origen y destino y las transformaciones que se producen.

La participación de las mujeres en los procesos migratorios tiene fuertes particularidades y explicaciones profundas relacionadas a dos fenómenos: por una parte, a las transformaciones económicas mundiales y a la reestructuración de los mercados laborales; y por otra, a la consolidación de redes sociales y familiares. Desde la perspectiva de la feminización, la "migrante ideal" es la mujer trabajadora que migra, sin pareja, motivada por cuestiones estrictamente laborales o económicas. Desde otro punto de vista, la movilidad de las mujeres hacia los países desarrollados está asociada al crecimiento de una "cadena mundial de cuidados", basada en la transferencia transnacional del trabajo reproductivo como respuesta a una crisis de los cuidados, que afecta a los países del norte y que produce una demanda de mano de obra femenina que ha acelerado los movimientos.

\section{Las condiciones de los procesos migratorios afectan más a las mujeres que a los varones}

La situación de la mujer migrante, en conjunto, es todavía más precaria que la de los hombres. Ciertamente, eso ocurre también en el colectivo espańol, no obstante no puede olvidarse que, en situaciones de marginación y pérdida de derechos, son las personas migrantes quienes más lo resienten. No reconocer esto, incluso entre quienes se esfuerzan por una sociedad más justa, dificultará hoy y mañana cualquier política de migración (Ródenas, 2001).

Por otra parte, Mary García Castro (1985), en su Trabajo versus vida: las inmigrantes colombianas en Nueva York, expone cómo un buen número de las colombianas inmigrantes, obligadas por una proletarización cada vez mayor, y en consecuencia golpeadas fuertemente por el desempleo, emigran a los Estados Unidos sin que logren escapar allí a la lógica de una sociedad que valora el trabajo en relación con el sexo e impone a la mujer oficios en los cuales la marginación resulta aún peor que en su propio país.

Quizás se pueda concluir que esas migrantes viven las mismas condiciones de desigualdad que en Colombia, con la gran diferencia de que su categoría de indocumentadas, de extranjeras, de separadas de la familia y de aisladas lingüísticamente, las convierte más fácilmente en víctimas de la opresión.

Las mujeres que migran hacia España viven paralelamente la misma situación, ya que muchas de ellas abandonan sus países con el peso de resolver todos los problemas económicos de sus familias. Este proyecto de vida tiene un gran precio y es el de asumir la gran presión psicológica que supone tener que dejar a sus hijos, hijas y sus familia, tener que trabajar en "cualquier cosa" y "bajo cualquier condición", persiguiendo la meta de obtener los ingresos económicos suficientes para enviar a los países de origen. 
Aunque en España las investigaciones sobre las inmigraciones contemporáneas son recientes, se han caracterizado generalmente por ser descriptivas del fenómeno, centrándose en colectivos socialmente aislados, observados como "distintos" y hasta "contrarios", unas veces catalogados como "peligrosos", irregulares y con problemas de adaptación dentro de la sociedad española. En los últimos años, autores como Solé (2004); Criado (2001); Izquierdo (2003) y Ramírez (1996), se encuentran profundizando en los análisis cualitativos de su integración social y cultural, así como de su participación y aportación al desarrollo y avance de la economía y de la sociedad. Sin embargo, existe un vacío en la percepción e investigación de un colectivo particular, para este caso el de la mujer inmigrante latinoamericana, y en especial la colombiana en su relación con el Estado del Bienestar, en ejercicio pleno de su integración social, cultural y económica.

A pesar de su importancia numérica, las mujeres colombianas migrantes representan un conjunto poco visible y muchas veces, en situación de irregularidad, están dedicadas a trabajos o tareas de fácil ocultación y de máxima reserva, casi siempre con sujeción a funciones domésticas, o al cuidado de menores o personas ancianas. Se encuentran confinadas a trabajos donde no llegan medidas algunas de regulación, con horarios exhaustivos y hasta nocturnos, que dan buena cuenta de la magnitud del problema. La situación de estas mujeres inmigrantes se relaciona con aspectos sociales, asistenciales, económicos, laborales y legales, de suma precariedad e inferioridad social.

\section{La mujer inmigrante colombiana es la responsable del bienestar de su núcleo familiar}

La situación de la mujer migrante, en conjunto, es todavía más precaria que la de los hombres. Ciertamente, eso ocurre también en el colectivo español, no obstante no puede olvidarse que, en situaciones de marginación y pérdida de derechos, son las personas migrantes quienes más lo resienten. No reconocer esto, incluso entre quienes se esfuerzan por una sociedad más justa, dificultará hoy y mañana cualquier política de migración (Ródenas, 2001).

Por otra parte, Mary García Castro (1985), en su trabajo Trabajo versus vida: las inmigrantes colombianas en Nueva York, expone cómo un buen número de las colombianas inmigrantes, obligadas por una proletarización cada vez mayor, y en consecuencia golpeadas fuertemente por el desempleo, emigran a los Estados Unidos sin que logren escapar allí a la lógica de una sociedad que valora el trabajo en relación con el sexo e impone a la mujer oficios en los cuales la marginación resulta aún peor que en su propio país.

Quizás se pueda concluir que esas migrantes viven las mismas condiciones de desigualdad que en Colombia, con la gran diferencia de que su categoría de indocumentadas, de extranjeras, de separadas de la familia y de aisladas lingüísticamente, las convierte más fácilmente en víctimas de la opresión.

Las mujeres que migran hacia España viven paralelamente la misma situación, ya que muchas de ellas abandonan sus países con el peso de resolver todos los problemas económicos de sus familias. Este proyecto de vida tiene un gran precio y es el de asumir la gran presión psicológica que supone tener que dejar a sus hijos, hijas y sus familia, tener que trabajar en "cualquier cosa" y 
"bajo cualquier condición”, persiguiendo la meta de obtener los ingresos económicos suficientes para enviar a los países de origen.

Aunque en Espańa las investigaciones sobre las inmigraciones contemporáneas son recientes, se han caracterizado generalmente por ser descriptivas del fenómeno, centrándose en colectivos socialmente aislados, observados como "distintos" y hasta "contrarios", unas veces catalogados como "peligrosos", irregulares y con problemas de adaptación dentro de la sociedad española. En los últimos años, autores como Solé (2004); Criado (2001); Izquierdo (2003) y Ramírez (1996), se encuentran profundizando en los análisis cualitativos de su integración social y cultural, así como de su participación y aportación al desarrollo y avance de la economía y de la sociedad. Sin embargo, existe un vacío en la percepción e investigación de un colectivo particular, para este caso el de la mujer inmigrante latinoamericana, y en especial la colombiana en su relación con el Estado del Bienestar, en ejercicio pleno de su integración social, cultural y económica.

A pesar de su importancia numérica, las mujeres colombianas migrantes representan un conjunto poco visible y muchas veces, en situación de irregularidad, están dedicadas a trabajos o tareas de fácil ocultación y de máxima reserva, casi siempre con sujeción a funciones domésticas, o al cuidado de menores o personas ancianas. Se encuentran confinadas a trabajos donde no llegan medidas algunas de regulación, con horarios exhaustivos y hasta nocturnos, que dan buena cuenta de la magnitud del problema. La situación de estas mujeres inmigrantes se relaciona con aspectos sociales, asistenciales, económicos, laborales y legales, de suma precariedad e inferioridad social.

\section{El derecho a la salud es fundamental para el bienestar de la mujer migrante colombiana}

El ejercicio pleno del derecho a la salud presupone que deben eliminarse las barreras que impiden el ejercicio, en condiciones dignas. Esto implica suprimir todo tipo de obstáculos sociales, económicos, culturales y de otra índole. De esta forma se puede afirmar que no se puede satisfacer el derecho a la salud si el individuo es privado del disfrute de otros derechos para lograrlo. Esos derechos son el derecho al trabajo, a la alimentación, a la vivienda, a la educación, al ambiente sano y a la participación activa de proyectos en salud, entre otros. En ese sentido, la satisfacción del derecho a la salud solo es posible en la medida en que se establezcan medidas legislativas y políticas integrales que aseguren el disfrute de los derechos humanos ya mencionados.

Es bien sabido por todos que el ejercicio pleno del derecho a la salud constituye un eje de bienestar y de desarrollo. Ningún cambio en el esquema de servicios de salud puede significar retrocesos en los niveles actuales del disfrute de este derecho. En otras palabras, la persona bajo cualquier condición, ya sea hombre o mujer, ciudadano, extranjero, regular o no, no puede renunciar a sus derechos humanos, ni el Estado a arrebatárselos. Esto implica que los derechos no pueden estar sujetos a negociaciones que menoscaben su vigencia. Así, los elementos esenciales del derecho a la salud son: la no-discriminación por ninguna índole o razón y la accesibilidad plena y total a los servicios sanitarios, para que este conjunto de factores constituya la base de un bienestar (Organización Panamericana de la Salud, 1991, p.23). 
El sistema sanitario español y según normativa en el año 2004, ofrecía los siguientes servicios sanitarios a los inmigrantes:

- Asistencia sanitaria a los extranjeros que se encuentren empadronados en España de forma habitual.

- Asistencia sanitaria de urgencia hasta la situación de alta médica.

- Asistencia sanitaria a los extranjeros menores de dieciocho años que se encuentren en España.

- Asistencia sanitaria durante el embarazo, parto y postparto.

La normatividad no define la situación especial de los extranjeros en situación irregular o de ilegalidad. Se permite al colectivo de inmigrantes el acceso a la asistencia sanitaria en las mismas condiciones que los españoles bajo el requisito del empadronamiento. Sin embargo, a escala estatal no existe una política sanitaria definida y clara en lo referente a la atención de manera integral, continua y con beneficios de promoción de la salud y de prevención de la enfermedad, limitándose, en algunos casos, a la atención de urgencias, generando una franca exclusión e inequidad (Vázquez, 2002).

No se contempla la necesidad de establecer una atención equitativa de acuerdo a sus necesidades, dicho de otra manera, un seguimiento particular a los tratamientos que venían siguiendo desde sus países de origen, interrumpiendo procesos de seguimiento y control.

Desafortunadamente, en la actualidad el horizonte ha empeorado de manera acelerada; dada la crisis que vive España y en el gobierno actual, se ha ofrecido un dinero a cambio de abandonar el país y regresar a los países de origen. Bajo el lema "para una reintegración positiva en el país de origen”, España quiere deshacerse de todos los inmigrantes indocumentados, incluidos los solicitantes de asilo que todavía no hayan recibido una respuesta, los menores no acompańados y las personas que no gocen de protección internacional.

El tema de los derechos sociales y sanitarios de los inmigrantes marca, sin lugar a dudas, una de las principales bases de bienestar y estabilidad de la población inmigrante. La salud como derecho se definió a lo largo del trabajo doctoral en un sentido amplio en el que se incorporan el medio físico y social, haciendo énfasis también en el impacto de las condiciones políticas, sociales y ambientales que influyen en ella. De esta forma se relacionó la salud de las mujeres migrantes colombianas con las condiciones de salida del país, las características de llegada, redes familiar y social, acceso a los servicios de salud, condiciones de trabajo, vivienda, y por lo tanto, con pobreza, distribución de ingresos y, en general, con condiciones de vida asociadas a la idea de justicia social.

A todo lo anterior alude la expresión de "bienestar", que apunta a la dimensión individual y social de este derecho, lo que implicó que la salud se considerara como parámetro de medición del desarrollo. En ese sentido, la salud constituye la base primordial para el fortalecimiento del capital humano, ya que la consecución del bienestar pleno de las personas es una condición indispensable para que estas puedan expresar sus potencialidades creativas y productivas. Desde esa perspectiva, el logro de los objetivos de salud implica trabajar en función del progreso social y no del mero avance económico (Roener, 1989). 
Los relatos de las mujeres colombianas y su trama personal en torno a la salud se evidenciaron durante las entrevistas en profundidad. Aquellas mujeres que no tenían su situación administrativa en regla, se acercaron con más confianza por mi condición de ser colombiana, hablar el mismo lenguaje y comulgar con los mismos códigos de comunicación regionales.

Tanto las entrevistas a los profesionales como a las mujeres inmigrantes constituyeron dos aspectos básicos y complementarios, que centran la experiencia de la mujer colombiana inmigrante en el ámbito de la salud. Los dos grupos interactúan en el horizonte de los acontecimientos, confluyendo bajo el mismo fenómeno. El juego que establece el profesional sanitario es desde una postura de solidaridad, de protección y de defensa de los derechos de las mujeres inmigrantes; en esa medida, la postura de las mujeres entrevistadas se dio desde la construcción y lucha de un nuevo bienestar. El lenguaje que se plasmó en el trabajo doctoral fue enriquecido desde la perspectiva personal y la experiencia propia de cada mujer entrevistada.

Las propuestas finales de este trabajo doctoral pretenden evidenciar la situación de la mujer inmigrante colombiana desde la consecución y construcción de un derecho fundamental: el derecho a su propia salud; siendo este el pilar de bienestar para el desarrollo de una vida laboral estable, de sustento y de proyección futura para ella y sus familias, fuera de los linderos nacionales.

Es importante dejar claro que en un mundo globalizado se hace pertinente reflexionar y plantear investigaciones que contemplen más allá de lo local, que la movilidad humana, sea cual fuere la razón, exige de los expertos y expertas, propuestas de un derecho a la salud y el bienestar que pertenezca al Derecho internacional, sin trabas, sin exclusiones y con múltiples diferenciales. Los proyectos migratorios son innumerables, lo que requiere de esfuerzos transdisciplinarios, transinstitucionales y transnacionales. La localidad es cada vez más remota, los linderos son cada vez más interrumpidos, la homogeneidad se debe centrar solo al acceso a los derechos y la construcción de políticas de salud debe apuntar cada vez más a situaciones diversas, amplias y complejas.

\section{Los relatos de las mujeres colombianas inmigrantes}

En este apartado incluiremos los relatos de mujeres provenientes de mi disertación doctoral, en que se recogen sus opiniones en contextos de migración. Según Serra Yoldi (2001), solo hasta la década de los noventa, aparece la migración de mujeres solas, algunas de ellas embarazadas, solteras, separadas con cargas familiares en el país de origen y que se desplazan en busca de trabajo. Las mujeres se han convertido en protagonistas de la migración, en actoras económicas, sociales y de desarrollo. En la actualidad, el $47 \%$ de los inmigrantes regulares que viven en Espańa son mujeres. El 70\% son solteras, viudas o divorciadas. El otro tanto de mujeres está casado o tienen hogares ya conformados.

Todos los datos censales indican la incorporación paulatina de la mujer al movimiento migratorio para hacerse cargo de los denominados "empleos de proximidad" y de otros trabajos del sector servicios, principalmente, de los servicios domésticos en el Régimen Especial de Empleadas de Hogar.

La inmigración de empleadas de hogar, como es bien conocido, no está exenta de la acción de individuos que con fines lucrativos, y de una manera más o menos indirecta, se benefician del 
éxodo y explotación de seres humanos. Muchas mujeres inmigrantes forman parte de una inmigración irregular de "servidoras", pertenecientes a un nuevo proletariado de servicios (domésticos y sexuales). En este fenómeno participan múltiples actores sociales que contribuyen a reproducir el círculo de la irregularidad, determinando, gracias a una serie de estrategias (deuda, controles fronterizos, devoluciones, expulsiones, inserción laboral y social) la consolidación de una clase de trabajadoras precarias (Casas, 2003).

Ellas requieren trabajar y desarrollar su cotidianidad. Trabajan con tesón y constancia. Demuestran energía y vitalidad, pero la salud se resiente y necesitan cuidados a sus quebrantos de salud. Por lo tanto, el motivo de consulta que lleva a las mujeres al Servicio Público de Salud, hace referencia a problemas médicos, relacionados generalmente con el estrés y con la ansiedad. Como lo comentan varios autores, Vásquez (2002); Berra y Serra (2003), el estado de salud de los inmigrantes no supone una amenaza por la posible introducción de enfermedades importadas. Como patologías reemergentes no existe ninguna enfermedad asociada a la inmigración. Normalmente, cuando se emplea ese término es para referirse a tuberculosis, sífilis y patologías similares, enfermedades que en España no han desaparecido nunca.

Ratifican estos estudios autores como Santamaría et al.(2002) al relacionar estos principales motivos de consulta: patología del aparato locomotor, relacionada con su trabajo y por accidentes laborales; patología del aparato respiratorio, como tuberculosis e Infección Respiratoria Aguda (IRA); patología gineco-obstétrica, como embarazos (deseados y no deseados), abortos provocados y Enfermedades de Transmisión Sexual (ETS) muy en relación con la prostitución; patología psiquiátrica y psicosomática, siendo estas la depresión, consumo de drogas y alcohol y esquizofrenia. De este último grupo de patologías podemos confirmar que los principales factores de riesgo son, sin lugar a dudas las condiciones de vida, la añoranza, la discriminación, el riesgo de expulsión y los problemas de inestabilidad laboral.

En general como pasa con todos los inmigrantes parece que cuando recién llegados al país de acogida, deberían presentar enfermedades propias de esos países, pero ocurre muy raramente. La mayoría de las veces, o bien presentan enfermedades que son universales y sobre todo cuando llevan tres o cuatro meses en el país, o presentan los mismos problemas que pueda tener cualquier nacional. En cuanto a los inmigrantes y en cuanto a las mujeres, sí que es verdad que muchas veces, yo les he detectado problemas debidos al desarraigo temporal: abandonar su país y no ser acogidos todavía por uno nuevo. Las mujeres traen consigo muchos problemas que se podían llamar somatizaciones, dolores articulares, vienen con muchas temas que no son específicos, que son muy ambiguos y que no se pueden calibrar. Y detrás de eso, siempre hay un problema: que no se han acoplado, que sus familiares están allá $[\ldots]$ muchos problemas. [E-VS]

Autores como Río Benito (2003) afirman que el grupo heterogéneo de inmigrantes no debe ser considerado como un grupo de riesgo. Plantean el principio el "efecto emigrante sano", considerando que la mayoría de los inmigrantes económicos tienen una salud normal que se ve afectada por factores derivados de su nueva condición.

Los pocos latinoamericanos que atiendo en mi consulta especializada han venido por problemas de colon irritable, o trastornos funcionales digestivos [...] Se asocia mucho a cambios de dieta, situaciones de estrés, inseguridad e incertidumbres [...] [E-RG] 
Esto (la migración) tiene un precio, un precio sobre la tristeza, yo pienso que suelen ser alegres en su país, el clima, la alimentación [...] además son personas muy jóvenes, máximo lo que he visto aquí son 45 años. [E-MAB]

La solución no es dar un medicamento, pues tienen a veces dolor de estómago [...] es porque están nerviosas, tensas por que trabajan en malas condiciones, mal pagadas, entonces tienen muchos problemas que son somatizaciones [...] [E-VS]

Aseguran que las inmigrantes son un colectivo, por lo general, muy sano, económicamente activas y en edades que no requieren mayor atención sanitaria.

Vienen los más sanos. Son fuertes y aguantan mucho. Son jóvenes y fuertes. Emigran los más fuertes. Es la ley de selección natural. [E-RG]

En general, suelen estar bastantes sanos, un porcentaje del 15\% tiene enfermedades parasitarias banales, es decir, que en su país no tienen ninguna importancia pero que en Espańa a los espańoles, no extranjeros, les puede ocasionar diarreas, etc., entonces es una patología orgánica, la más frecuente. Y después está la patología psicológica, es el Síndrome del Inmigrante. [E-AQ]

Consultan por temas de planificación familiar, dependiendo de la edad a lo mejor tienen alguna enfermedad crónica que necesita ser revisada y controlada y en algunos casos también hemos tenido interrupciones voluntarias de embarazo [...] El motivo es igual que el de las españolas, la situación económica, la situación familiar, el no tener una pareja estable. [E-AC]

\section{Yo fui alguien. Ahora no soy nadie}

Cuando ellas recordaron quienes eran y a qué se dedicaban en Colombia antes de emigrar, reconocieron que se desprendieron de una estabilidad social y, en cierto grado, económica, viendo uno de los precios que hay que pagar cuando se sale del país. Han renunciado a un pasado, quizás más prestigioso, que el presente actual, para venir a asumir situaciones y labores que no corresponden con su capacidad intelectual. En general, la sociedad espańola ubica en un mismo conjunto a todos los inmigrantes. Los rotulan bajo un mismo denominador, como personas con escasos conocimientos, sin estudios superiores o sin respaldo económico. Hasta ahora, las investigaciones empiezan a identificar en ellos agregados académicos e intelectuales que perfilan individuos mejor cualificados. Si bien es cierto que, en un primer momento, emigran aquellos que tienen dificultades de orden económico, estas afectan, inicialmente, a los sectores menos favorecidos de la economía. A medida que avanza la crisis económica en los países subdesarrollados, se van viendo afectadas personas licenciadas y con puestos mejor posicionados dentro de la escala laboral. Es por esta razón en la que, cada vez, emigran personas con un nivel educativo superior. Uno de los principales obstáculos con los que se estrellan las mujeres inmigrantes latinoamericanas, es que por lo general se las sitúa como personas que solo son capaces de desarrollar actividades que no exigen mayor preparación.

En todo caso me dedicaba a hacer cursos de capacitación de corta duración en varias áreas y trataba de estar distraída y siempre con miras a mejorar mi formación. Me puse a investigar cuales eran las oportunidades de formación que le ofrecían a la mujer inmigrante latinoamericana y verdaderamente no son muchas. Las opciones se reducían a aprender a atender a personas mayores o a discapacitados, recoger fruta, o ser camarera [...] Por mi formación ninguna de estas áreas me llamaba 
la atención. Sin embargo me sentía más orientada hacia el cuidado de personas mayores por mi formación en Salud.[R4]

Es necesario dejar claro que todas las actividades de la economía son necesarias para el funcionamiento de la sociedad. No se deben clasificar actividades de "primera clase" o "de segunda clase". El error es orientar un recurso humano, en este caso inmigrante, en actividades de baja preparación y en las cuales no es valorada su capacidad intelectual. Las primeras consecuencias son sentimientos de frustración y de baja auto-estima.

Actualmente hago limpiezas. Soy empleada de hogar. Trabajo por horas básicamente. No me gusta cuidar niños. Prefiero hacer limpiezas. Nunca me ha faltado trabajo. A los ocho días de estar acá, ya tenía trabajo. Siempre he estado activa. Económicamente no estoy mal. Lo que pasa es que no es a lo que uno estaba acostumbrado. Yo en Colombia me relacionaba con gente académica, con estudiantes con profesionales. Ahora me relaciono con personas que trabajan en limpiezas y eso hay veces hace que me sienta sola y no me relacione con facilidad. [R3]

Es importante recalcar que todas las mujeres entrevistadas tienen estudios superiores, excepto dos que poseen estudios básicos. En Colombia, y sobre todo en el espacio de las grandes ciudades, es un prestigio y un valor tener formación académica. Parte de la forma en que se reconocen y se identifican a las personas, sobre todo a quienes viven en las grandes urbes, no es por los oficios que desarrollan, sino por los estudios que poseen. Esto es debido, en parte, a la inevitable "urbanización” de la cultura. Se dejó de lado a las personas que ejercen un oficio. La mano de obra, siempre mal remunerada, se desvalorizó aún más y no se le reconoció, ni se le reconoce aún, su verdadero valor. De esta forma, los cargos de mejor remuneración son aquellos donde se "profesionalizaron" las actividades. La educación ha sido y sigue siendo un privilegio. El desarrollo de la cultura urbana compite con la cultura que está más allá de las ciudades. Este fenómeno produjo el inevitable abandono de los campos y de los oficios del sector primario de la economía.

Paralelamente, en Espańa los puestos de trabajo que generalmente no ocupan los nacionales son aquellos oficios que son mal remunerados en Colombia. Esta situación atrajo, en los inicios de la inmigración, a muchos trabajadores, como ayudantes de la construcción, carpinteros, conductores, y empleados de los servicios de proximidad que no poseían estudios superiores. Durante las dos últimas regularizaciones, dichas personas lograron legalizar su situación administrativa y pudieron trabajar y enviar importantes cantidades de dinero correspondiente a las remesas. Sin embargo, en Colombia la crisis económica aumentó de manera drástica y se produjo un verdadero éxodo de colombianos calificados, en busca de un mejor porvenir.

De esta forma, el conocimiento que en España se tiene sobre la población inmigrante colombiana, no corresponde muchas veces con la realidad. En Espańa, las investigaciones que abordan el tema de la inmigración, han superado en términos generales la situación de orden demográfico: de dónde vienen, cuántos son, dónde residen y a qué se dedican. En este momento, lo importante es conocer a fondo quiénes son, cuáles son sus necesidades, tanto físicas como sociales, y en qué estado va su proceso de integración social.

Mucha gente se asombra cuando me preguntan a que me dedico: Les cuesta trabajo creer que estoy haciendo un Máster. Sobre todo si saben que soy colombiana. [R7] 
Cuando la seńora a quien le hice la limpieza de su piso supo que yo era estudiante de doctorado, no lo podía creer. Eso fue hace más de dos años. Ya en este momento están cada vez más acostumbrados. Piensan que uno, porque viene de un país subdesarrollado, no sabe leer ni escribir. [R1]

\section{El reconocimiento de un cuerpo distinto: un cuerpo solo y dolorido}

Cuando el cuerpo tiene que adaptarse a nuevas condiciones, hace que las mujeres se fijen en detalles que antes eran considerados como superficiales o casi inadvertidos.

Los comentarios, con respecto a las estaciones climáticas, hacen prever que son sentidas y apreciadas, muchas veces, como factores de riesgo y no como eventos de la naturaleza. Provienen de un país donde las estaciones no existen y, por lo tanto, no tienen en mente el cambio atmosférico. El adaptarse a la nueva gastronomía y sentir un clima diferente, que muchas veces son nuevas para el cuerpo, se convierte, en un principio, en dificultades para desarrollar una estabilidad fisiológica. El cuerpo es distinto en España Refieren

El cuerpo ha cambiado desde su llegada y se manifiesta, por lo general, con un aumento o pérdida de peso; dolores y cansancio en las piernas y los pies. La piel cobra otro aspecto y lo refieren como a un resecamiento, manchas o procesos de acné. El pelo se torna distinto, quizás, reseco, porque el agua es muy pesada. También relatan la mayoría, que el pelo se les cae, y les cambia la textura.

Lo primero fue que bajé muchísimo de peso, sin querer, sin hacer dieta, la verdad es que vivimos un ambiente muy duro, yo lloraba [...] veinticuatro horas que tiene el día, lloraba cuarenta y ocho. Ha sido muy duro, para que te voy a contar[...] Se envejece mucho más rápido, el deterioro es más rápido. También me di cuenta que no solo la parte emocional que se vive y el cambio que tú tienes que hacer de trabajo y normalmente, no estás trabajando en lo que tú sabes hacer y lo que has hecho siempre y tienes que apechugar con eso, sino las diferentes estaciones que nuestro cuerpo no está acostumbrado, tiene mucho que ver, afectan demasiado. [R10]

Si. Me adelgacé por la tristeza y el dolor. Perdí casi 10 kilos. Me dolían mucho los huesos. La piel se me resecó mucho, se me manchó la piel. Me sentía muy deprimida. La regla no me venía y como aquí, cuando uno llega, se le atrasa o se le adelanta la regla, pues yo que me iba a imaginar que estaba embarazada. [R9]

Las estaciones son lo que más lo afectan a uno. El invierno a mí me pone fatal. Tiendo más a la tristeza y a la nostalgia. Aunque soy una persona muy alegre, ese período me afecta mucho. Prefiero la primavera y el verano. Mi cuerpo no está acostumbrado a las estaciones. [R5]

El invierno me deprime. Me dan ganas de quedarme en la casa todo el día. Prefiero el sol porque me recuerda el sol de mi ciudad. [R1]

Por lo general relatan un gran cansancio y una fuerte falta de energía.

[...] en Colombia yo madrugaba con una gran facilidad. Ya estaba lista a las 6 y 30 de la madrugada

[...] Acá, me cuesta mucho levantarme. Me siento como si tuviera un ladrillo sobre los ojos. [R7]

Es cierto que en los primeros meses el metabolismo se altera. En efecto, cuando llegan, el cuerpo requiere de un tiempo para adaptarse. Cuando la persona lleva más de un año, su organismo se ha acostumbrado, poco a poco. 
[...] al principio me resfriaba mucho, y no sabía qué cosas comer. Todo me sabía raro....Ahora conozco más las costumbres. Al principio todo es más duro porque uno no sabe nada. Todo cuesta trabajo. [R3]

Las alteraciones de orden hormonal son debidas, generalmente, a situaciones de estrés. El cuerpo puede aumentar o disminuir de peso, así como presentarse ciclos de amenorreas o dismenorreas que alertan a las mujeres. Los ciclos menstruales se alargan o se acortan, o sencillamente desaparece la función fisiológica.

[...] una de las cosas que me acuerdo es que la regla no me llegaba, sin ninguna explicación. [R1]

Las disfunciones de orden dermatológico, son catalogadas como situaciones de orden psicosomáticas y representan evidencias de estrés.

Mi piel se manchó y se me resecó [...] y otro de las cosas que me pasó, es que la cara se me llenó de granitos que antes yo no tenía. [R3]

Sí, el agua me ha parecido fatal, el pelo no es lo mismo, la piel, los dientes de hecho tampoco, a mí me preocupa mucho. El agua es pésima. Sí [...] Sí, y son cambios muy notables. Lo sentía, lo sigo notando.[R10]

El peso de trabajos extenuantes, el estrés al que se enfrentan y las condiciones injustas bajo las cuales tienen que realizar los trabajos, produce dolores en diferentes partes del cuerpo. Muchos de esos cuerpos no estaban acostumbrados a soportar trabajos físicos y ahora son "exigidos" ante duras jornadas. Los dolores son diarios. No son esporádicos. El dolor sorprende al principio, en la llegada, pero acompaña al cuerpo por donde vaya. Solo en las noches se descansa. Son manifiestos los dolores de espalda y sobre todo de piernas.

Siento mucho dolor en las piernas. Me duelen los huesos y creo que es por la humedad. Como no estoy acostumbrada a las estaciones ni a la humedad, pues creo que más me afecta. Tenemos un clima tropical, constante y sin estaciones que no afecta tanto la salud. [R3]

El hecho de que muchas de ellas se dedicaban en Colombia a trabajos intelectuales más que físicos, hace que sus cuerpos reaccionen y se rebelen ante su nueva condición.

En Colombia mi trabajo era esencialmente académico y profesional y no físico como ahora. Entonces yo creo que mi cuerpo lo resiente y por eso lo siento distinto. [R6]

Las manifestaciones de dolor van desde reconocer que no pueden hacer nada para evitar esas complicaciones, hasta darse de baja y literalmente "rendirse" por la incapacidad de seguir trabajando.

Este trabajo no genera salud. Pero tampoco me enfermo porque soy muy fuerte. Alguna vez amanecí con los pies inflamados y con las manos inflamadas y con sangre de tanto trabajar y simplemente me tomé dos o tres pastillas para el dolor y así solucioné el problema [...] Trabajaba dieciséis horas al día. Me sentía al otro día agotada. [R6] 
Ante palabras significativas, como "hijos" o "familia" se generaron momentos de una gran intensidad emocional. En diversas ocasiones tuve que interrumpir las grabaciones ante los profundos recuerdos hacia los hijos distantes y las familias dejadas en la lejanía. Las voces se quebrantaron más de una vez, y he de confesar que me identifiqué con ellas y compartimos juntas el dolor de dejar los seres queridos.

Estas situaciones de duelo dotan de una gran fragilidad a las personas y se convierten en la etiología de diversas enfermedades. Las mujeres reconocen que la nostalgia las acompaña.

Nadie sabe el dolor que representa dejar a un hijo [...] Yo lloro en las noches [...] En silencio, cuando nadie me oye $[\ldots]$ claro que uno siente nostalgia $[\ldots]$ y quien no, $[\ldots]$ Uno es humano $[\ldots]$ Eso ya hace parte de mí. Hay momentos que me matan [...] Cuando más extraño a mi familia es cuando tengo que tomar una decisión y no los tengo junto a mí [...] La sensación de fragilidad y de "pequeñez", se convierten en dos enemigos con los cuales hay que combatir día a día. [R1]

La falta que me hacen mis padres no te lo puedes imaginar [...] Hay veces que me provoca salir corriendo de aquí. [R7]

Quizás uno de los aspectos más delicados es cuando relatan los momentos de soledad. El ser humano, como ser social, necesita de un entorno rodeado de afecto y de respaldo. Esos entornos no están conformados tan solo por la familia, sino por el círculo de amigos y por los compañeros de trabajo. Los aislamientos son consecuencia de no conocer la ciudad, los códigos de comunicación, los lugares de referencia y los lenguajes de socialización. Las relaciones y el entramado social son frágiles y los momentos y aspectos de la vida cotidiana se tornan difíciles y complicados. Esta sensación de soledad, convierte al inmigrante en presa de una gran vulnerabilidad física y mental.

\section{Quien cuida a la cuidadora: la soledad en la enfermedad}

¿Quién te cuida en España? Esta fue sin duda una de las preguntas que se comportó como un detonante. Reveló la fragilidad de la soledad. Aunque la respuesta estaba impregnada de una gran fuerza y de una singular valentía, descubrió, a más de una, un ser frágil y hasta atemorizado.

En todo caso, es de las cosas que me dan miedo: enfermarme en España y no tener a algún miembro de mi familia para confiar y apoyarme [...] En todo caso me cuido sola y trato de no molestar a nadie. [R1]

[...] Es triste al fin y al cabo, porque yo estaba acostumbrada a que mi familia me cuidaba. La soledad en la enfermedad es muy dura No hay cosa más horrible que nadie le pase a uno un vaso de agua. En esos días que estuve enferma, mis dos amigas no pudieron ayudarme: la una estaba de viaje y la otra estaba también enferma. [R7]

Yo misma. Me considero una mujer muy sana y muy fuerte. No quiero volverme dependiente de nadie. [R6]

Si ellas vienen con la familia algún miembro acude en su ayuda, pero de lo contrario, si la enfermedad lo exige: llamo a mis amigos. [R4]

Como bien lo comentan Durán et al. (1987), un tipo distinto de auto cuidado es el que podría llamarse "forzoso", derivado de la carencia de apoyos familiares o de otro tipo. Es una 
situación relativamente frecuente en los enfermos que viven solos y, especialmente, entre los inmigrantes. Ya cuando han tenido que atravesar la experiencia de la pérdida de la salud, la valoración de la ayuda de otras personas y la necesidad de estar acompañadas resulta absolutamente necesaria.

Las redes sociales juegan un papel decisivo en la salud de las personas y sobre todo de los inmigrantes. La habilidad para pertenecer a círculos ya formados, de hacerse integrar dentro de los suyos y de jugar los respectivos roles, conforman uno de los primeros pasos dentro de la estabilización emotiva y social. De la forma en cómo se desarrolle este tejido social, de la misma forma se está asegurando su supervivencia.

Yo solo tengo amigos españoles. Colombianos, me sobran en los dedos de las manos. Si mi hija no está conmigo, sé que alguno de mis amigos me ayudaría. [R2]

[...] Al principio nadie nos ayudaba. Aunque éramos varios en el piso, esos primeros días eran horribles. Yo me sentía más sola que nunca. Mi esposo tuvo que dejar de trabajar para ayudarme. Yo estaba muy enferma [...] Yo tuve a mi hija sola, porque mi esposo tenía miedo de perder el empleo. Yo estaba completamente sola. [R9]

\section{El trabajo de las mujeres inmigrantes y su relación con la salud}

La inmigración económica genera esta situación de entrega casi “incondicional” por el trabajo, hace que ellas dejen de lado otros valores, como el de la salud. Como comentan Castillo y Mazarrasa (2001), el valor de los trabajadores inmigrantes es medido en función de su producción. Los momentos de enfermedad debilitan y hasta rompen la relación laboral. Aunque la salud no es apreciada, la enfermedad supone dejar de producir. Esta situación las obliga a experimentar situaciones extremas. En estas relaciones, las mujeres se guardan mucho de no dejar en entredicho su capacidad de trabajo y el buen desempeño de sus tareas. El temor a perder el trabajo es constantemente repetido bajo términos de responsabilidad y disciplina.

En todo caso uno llega a Espańa no para hacer uso de los servicios de salud sino para arreglar los papeles, para buscar trabajo y para poder ahorrar. La salud está en un segundo plano, totalmente olvidada [... Me dedico a trabajar y se me olvida la tristeza porque mantengo mi mente distraída. Estoy acostumbrada a sentirme sola [...] Vine a trabajar y crearme un espacio para buscar papeles [...] En estos momentos mi cuerpo es una herramienta de trabajo. Espero que sea por un tiempo pasajero. Espero que no sea para toda la vida. Espero que con el trabajo pueda superarme. Cuidar mi salud no es importante para mí. [R6]

[...] Pero mi trabajo al final me distrae. Yo soy una mujer fuerte [...] Vine a estudiar y a trabajar y eso hago. Yo hago jornadas de casi trece horas diarias, y no me quejo, estoy acostumbrada a trabajar [...] Yo tengo derecho a ir al médico, pero no puedo enfermarme. Estos tres días que he estado de baja, mis jefes me llaman diciéndome que no me puedo enfermar y que me necesitan. Han llegado al extremo de hacerme ir, estando enferma para que yo ayude en algo. Eso sucedió por dos días. [R7]

Exigen y someten sus cuerpos a situaciones extremas y se convierten en "máquinas de trabajo", condicionadas casi siempre por la figura de sentirse "extranjeras inmigrantes que las coloca en franca desventaja. 


\section{Conclusiones}

A través de este rastreo pretendo dejar sobre la mesa la importancia de reafirmar que la movilidad humana, dentro de ella las migraciones, son parte de la condición humana. La historia de la humanidad ha sido la historia de grandes migraciones, por las cuales el ser humano se fue desplazando desde sus lugares de origen en África, hasta poblar prácticamente todo el planeta. Este proceso de migración constante ha sido la condición natural de vida de las sociedades primitivas. El ser humano ha migrado por diversas causas, desde la meramente ecológica, por razones bélicas, culturales, económicas, políticas, familiares o sociales, hasta motivos de grandes catástrofes naturales.

La movilidad humana debe ser tenida en cuenta en todos los aspectos del bienestar del individuo y de las colectividades y, por ende, a la hora de plantear políticas y normativas que solo contemplen sociedades estáticas e inamovibles, va en contravía de una realidad que es cada vez más globalizada y que traspasa fronteras.

La mujer siempre ha migrado junto al hombre, a pesar de no haber sido reconocida. Su gran rol era, y sigue siendo muchas veces, ser la responsable del bienestar y cuidado del varón y de la familia. En las últimas décadas ella es quien protagoniza los proyectos migratorios, para convertirse en el eje de las remesas que van a los países de destino y esto la convierte en la proveedora económica, no solo de sus hijos e hijas, sino de sus padres, familiares cercanos y hasta de sus maridos. Esta es la llamada "feminización de las migraciones".

Cuando la mujer inmigrante se inserta en el ámbito laboral, esta circunstancia se refleja en el deterioro de su cuerpo, de la psiquis y de su salud emocional. Está sujeta a una triple discriminación, como bien lo dice Carlota Solé en sus múltiples investigaciones: por ser mujer sujeta a discriminaciones sociales y culturales en los países de origen y de destino, por el tipo de labor que desarrolla en los servicios de proximidad no reconocidos ni valorados en la sociedad de destino y por su origen étnico, generalmente estigmatizados.

Fisiológicamente el cuerpo de las mujeres inmigrantes requiere adaptarse a las nuevas condiciones de vida en España. Se genera regularmente un período de inestabilidad emocional, psicológico, social y laboral, donde se presentan signos y síntomas propios del desarraigo: todos estos síntomas y signos ya han sido reconocidos desde la psiquiatría transcultural y no pocos expertos ya trabajan en este espacio investigando, conociendo, explicando y conceptualizando sobre los diferenciales que aquejan a los colectivos que migran.

De acuerdo a la publicación de Pérez Sales (S.f.), las disciplinas que conceptúan sobre la realidad transcultural tienen un desarrollo importante, pero escaso. A pesar de que existe un conjunto para nada despreciable de publicaciones a lo largo de los últimos ańos, se puede decir que existen solo algunas líneas de investigación pioneras, pero que desafortunadamente llegan a repetirse. En resumidas cuentas, una aproximación de esta literatura refleja las siguientes tendencias:

- Son estudios en los que la unidad de análisis son los mismos países. Hay, por tanto, una ausencia de gran trascendencia. Por ejemplo, se consideran estudios transculturales los que comparan valores entre países, sin tener en cuenta que en el mismo país existe más de una cultura. Este tipo de estudios, dudosamente se pueden catalogar como transculturales. 
- Otro conjunto de estudios de psicología social transcultural corresponden en realidad a estudios de diferencias respecto a determinada variable entre diferentes grupos étnicos entre dos países y desde ese punto, es muy difícil separar los efectos generacionales de los efectos culturales comunes.

- Los estudios auténticamente transculturales en el sentido estricto de la palabra realizan comparaciones entre sociedades colectivistas e individualistas. Se requeriría de estudios que combinaran variables individuales y sociales para poder analizar la interacción entre ellas, asumiendo que en cada cultura existen mayor o menor frecuencia de determinadas actitudes o formas de respuesta, pero que no hay una relación de correspondencia (Smith P.B. \& Harris Bond, M. (1998); Markus H \& Kitayama S. (1991).

De acuerdo con la publicación de Castillo, Victoria, et al. (2006), las mujeres que fueron entrevistadas para esta investigación relataron de manera nostálgica dejar a sus familias en la distancia y el tener que soportar trabajos a los cuales no estaban acostumbradas. Esta es la llamada "movilidad laboral descendente." Para explicar mejor este término, la literatura estudia diferentes aspectos de la movilidad laboral. Esta puede ser "inclusiva” o de "exclusión” del mercado de trabajo y se refiere cuando el trabajador transita hacia el desempleo, la inactividad o el empleo precario. También la movilidad laboral puede ser "interna" o "externa", y esta se refiere cuando el trabajador consigue una nueva posición en la misma empresa o cambia de empleador (Diprete, 1993). La movilidad puede ser también "voluntaria" o "involuntaria", si se trata de despidos o de renuncias (Hachen, 1988); y por último, la movilidad puede ser "ascendente", "descendente" o "lateral", en los casos en los que se evidencian diferencias entre el salario, cargo y prestigio del empleo anterior y el del nuevo empleo (Shin, 2004).

Para construir espacios sociales democráticos, tanto en los países de origen como en los de destino, se requiere una visión en donde no se admitan segregaciones, discriminaciones, negaciones de oportunidad, prejuzgamientos y estigmatizaciones que solo conllevan dolor y frustraciones. La democracia no se debe construir solo desde una visión local, en un mundo global, sino que este constructo políticos, administrativo y social, debe trascender naciones y fronteras. La categoría analítica del transnacionalismo resulta particularmente beneficiosa para ir más allá de la mera dicotomía "global-local” y "origen-destino", además de tener la capacidad de ser inclusiva, integradora y articuladora en los espacios micro, meso y macroestructurales que intervienen en las migraciones (Ciurlo, A., 2014).

Como persona migrante que fui y que sigo siendo por propio derecho, está en nuestras manos abrir espacios académicos transversales, holísticos, integrales y complejos que den cuenta de la realidad que nos rodea. Y sobre todo, evidenciar que la discriminación no solo está en la otra orilla, está en la nuestra, casi de manera estructural, lo que demanda una revisión intrínseca de nuestros modelos sociales, culturales y económicos. Finalmente, quiénes más que nosotras y nosotros mismos estamos demandados a la construcción de una nueva sociedad. 


\section{Referencias}

1. Asamblea Parlamentaria, Consejo de Europa (2000). Condiciones sanitarias de los inmigrantes y refugiados en Europa (Comisión de migraciones, refugiados y demografía. Ponente: Lord Ponsoby). Reino Unido: Grupo Socialista.

2. Atxotegui, J. (2000). Los duelos de la migración: una perspectiva psicopatológica y psicosocial. En E. Perdiguero y J.M. Comelles (comp.), Medicina y cultura (pp. 88-100). Barcelona: Editorial Bellaterra.

3. Atxotegui, J. (2002, marzo 21). El diàleg entre les cultures (ponencia en la Facultat de Psicologia, Ciències de l'Educació i de l'Esport). Catalunya: Universitat de Blanquerna.

4. Bernstein, B. (1993). La construcción social del discurso pedagógico. Textos seleccionados (Mario Días, editor y traductor; revisión de Ceneyra Chávez). Bogotá: Producciones y Divulgaciones Culturales y Científicas "El Griot".

5. Casas O. L. (2003). Estrategias migratorias de las mujeres ecuatorianas y colombianas en situación irregular: servicio doméstico y prostitución en Galicia, Madrid y Pamplona. Coruña: Universidade da Coruńa, Facultade de Socioloxia.

6. Castillo, S. \& Mazarrasa, L. (2001, junio). Salud y trabajo: una relación problemática en los discursos de las mujeres inmigrantes. Madrid: Ministerio de Cultura, Instituto de la Mujer, Ofrim/Suplementos.

7. Castillo, V.; Novick, M.; Rojo, S. \& Yoguel, G. (2006, agosto). La movilidad laboral en Argentina desde mediados del decenio de 1990: el difícil camino de regreso al empleo formal. Revista de la CEPAL 89.

8. Ciurlo, A. (2014, enero-junio). Género y familia transnacional. Un enfoque teórico para aproximarse a los estudios migratorios. Rev. Cient. Gen. José María Córdova 12(13), pp. 127-161.

9. Cots, F., ed. (2002): Perfil de la casuística hospitalaria de la población inmigrante en Barcelona. En F. Cots, X. Castells, C. Ollé, R. Manzanera, J. Varela y O. Vall, Gaceta Sanitaria 16(5), pp. 376-84.

10. Criado, M. J. (2001, octubre). La línea quebrada. Historias de vida de migrantes (tesis doctoral laureada). Madrid: Consejo Económico y Social CES, Departamento de Publicaciones NICES, Colección de Estudios 113.

11. Diprete, T. (1993): Industrial Restructuring and the Mobility Response of American workers in the 1980s. American Sociological Review 58(1), pp. 74-96.

12. Durán, M. A.; Heras, D.; García, C.; Caillavet, F. \& Moyer, M. (1987). De puertas adentro. Madrid: Ministerio de Cultura, Instituto de la Mujer, Serie de estudios 12.
13. Fernández, F. (1941). La Alhambra (fotografías de Diego Guevara de Pozo; dibujos a pluma de A. Garrido del Castillo, $3^{\mathrm{a}}$ ed.). Barcelona: Editorial Juventud.

14. Gomes e Souza, A. M. (s. f) La odisea de Penélope: proceso migratorio y malestares psicológicos (ponencia). Universitat de Valencia. Institut Universitari d'Estudis de la Dona. Recuperado de http://www.uv.es/iued/actividades/articulos/odisea.htm

15. Hachen, D. (1988). Industrial Labor Markets and Job Mobility Rates. Research in Social Stratification and Mobility 7, pp. 35-68.

16. Izquierdo Escribano, A. (2003, junio). Inmigración: mercado de trabajo y protección social en Espańa. Madrid: Consejo Económico y Social, Departamento de publicaciones. Colección de estudios 141.

17. Juliano, M. D. (1994). La construcción de la diferencia: los latinoamericanos. Papers 43, pp. 23-32.

18. López Abuin, J. M. (2002). El médico de familia ante el abordaje socio-sanitario del inmigrante. Actualización en inmigración. Revista FMC 9(7), pp. 492-7.

19. Markus, H. \& Kitayama, S. (1998). Culture and the Self: implications for cognition, emotion and motivation. Psychological Review 98, pp. 224-253.

20. Martínez Pizarro, J. (2003). El mapa migratorio de América Latina y el Caribe, las mujeres y el género. Santiago, Chile: CEPAL, Naciones Unidad, Serie 44 de Población y Desarrollo,

21. Meletti, J. (2004, abril 24). Licenciadas que limpian mocos. En Un proyecto europeo, Diario El País, sección internacional "Le Monde, La Repubblica, El País", sábado 24 de abril, pp. 8.

22. Morokvásic, M. (1996, février). Migrations au féminin en Europe. Passages.

23. OIT [Organización Internacional del Trabajo] (2001). La seguridad social en la perspectiva del año 2000. Ginebra: OIT.

24. ONU (2006). Estado de la población mundial 2006. Hacia la esperanza: las mujeres y la migración internacional. Nueva York: ONU/UNFA.

25. Parella Rubio, S. (2003). Mujer, inmigrante, trabajadora: la triple discriminación. Barcelona: Anthropos.

26. Pérez Sales, P. (s/f). Antropología psiquiátrica y psiquiatría transcultural. Recuperado de http://www.pauperez.cat/ index 2 .php?option $=$ com_docman\&task=doc_view\&gi$\mathrm{d}=7$ \&Itemid $=9$.

27. Perrot, Michelle (2009). Mi historia de las mujeres. Buenos Aires: Fondo de Cultura Económica. 
28. PWH [Price Waterhouse Coopers] (1999). Cuantificación de los gastos e ingresos que genera la presencia de inmigrantes en Espańa. Madrid: Instituto de Mayores y Servicios Sociales Estudio (Imserso).

29. Ramírez Goicoechea, E. (1996). Inmigración en España: vidas y experiencias. Madrid: Centro de Investigaciones Sociológicas.

30. Ramos, M.; García, R.; Prieto, M. A. \& March, J. C. (2001). Problemas y Propuestas de mejora en la atención sanitaria a los inmigrantes económicos. En M. Ramos, R. García, M. A. Prieto, J. C. March, Gaceta Sanitaria 15(4), pp. 320-326.

31. Rico, N. (2006). Las mujeres latinoamericanas en la migración internacional. Ponencia en seminario: Las mujeres trabajadoras inmigrantes y sus aportes al desarrollo del país de acogida y de origen, Madrid, Junio 22-24. En: http://www. cepal.org/mujer/noticias/noticias/2/25802/NievesRico.pdf

32. Río Benito, M. J.; Álvarez Girón M.; García Gil, C. \& Solano Parés A. (2003). Las mujeres inmigrantes en Sevilla: salud y condiciones de trabajo. Una revisión desde la medicina social. Revista Española de Investigaciones Sociológicas REIS, pp. 123-143. Sevilla: Universidad de Sevilla, Centro de Investigaciones Sociológicas CIS.

33. Ródenas, S., Bernardo (2001, junio). Mujer e Inmigración. Revista AequAlitas 6. Zaragoza: Instituto Aragonés de la Mujer y la Facultad de Derecho de la Universidad de Zaragoza.

34. Roener, R. (1989). El derecho a la atención de la salud. En OPS, El derecho a la salud en las Américas (publicación Científica n. ${ }^{\circ}$ 509). Washington: Organización Panamericana de la Salud.

35. Romani, O. (2002). Actualización en inmigración: la salud de los inmigrantes y la de la sociedad. Una visión desde la antropología. Revista FMC 9(7), pp. 498-504.

36. Santamaría, F.; Ganoso Martín, S.; Guerra Bobo, A.; Martín Vivas, C.; Ruiz-Escribano Taravilla, E. \& Zúñiga Guerrero, A. (Sin Fecha). Inmigrantes y atención sanitaria en España (en línea). Recuperado de http://uam.es/departamentos/ medicina/preventiva/especifica/congresoXV-18.html.

37. Serra Yoldi, I. (2001). Inmigración femenina, diversidad cultural y trabajo. En: M.A. Durán; I. Serra Yoldi \& R.
Torada (2001). Mujer y trabajo. Problemática actual. Valencia: Germania Serveis Gráfics, s.l. Alzira.

38. Shin, T. J. (2004). Structural Changes and Job Mobility Rates in the United States: Labor Market Turbulence and Growing Inequality. Berkeley: Institute of Labor and Employment.

39. Smith, P.B. \& Harris Bond, M. (1998). Social Psychology across cultures (2nd ed.). London: Prentice Hall Europe.

40. Solé, C. (2004, marzo 24-25). La mujer inmigrante: una triple discriminación. En: Entre la soledad y el coraje: Las mujeres que emigran solas (Jornada del Institut Universitari D’Estudis de la Dona. Coordinadora Inmaculada Serra Yoldi). Valencia: Universidad de Valencia.

41. Standing, H. (1998). Reflections on Gender and Health Reforms in the Context of Severe Health Inequalities (ponencia en la Organización Panamericana de la Salud, Grupo consultivo sobre Equidad de Género y Reforma). Washington, DC: Organización Panamericana de la Salud.

42. Tapia Ladino, M. (2011). Género y migración: trayectorias investigativas. Revista Encrucijada Americana 4(2), pp.115-147.

43. Tizón, J., ed. (1986). La migración como factor de riesgo para la salud. En J. L. Tizón, J. Atxotegui, J. San José, F. Sainz, N. Pellejero, M. Salamero, Gaceta Sanitaria 5(28), pp. 149-155.

44. Todorov, T. (2002). Memoria del mal, tentación del bien. Indagación sobre el siglo XX (trad. de Manuel Serrat Crespo). Barcelona: Ediciones Península.

45. Vaquiro Rodríguez, S. \& Stiepovich Bertoni, J. (2010). Cuidado informal, un reto asumido por la mujer. Ciencia $y$ enfermería 16(2), pp. 17-24.

46. Vázquez Villegas, J. (2002). Inmigración y salud: legislación. Actualización en inmigración. Revista FMC 9(7), pp. 505-8.

47. Vélez M. C. (1986). La mujer colombiana como objeto (de estudio). Comentarios sobre el libro: Mujer y familia en Colombia de Elsy Bonilla C. (Comp.). Bogotá: Plaza y Janés Editores. Boletin Cultural y Bibliográfico 7(32).

48. Zlotnik, H. (2003). The global dimensions of female migration. Migration Information Source. Migration Policy Institute. Recuperado de http:/www.migrationinformation.org/Feature/print.cfm?ID=109. 